\title{
A utilização de técnicas de pesquisa do usuário para a definição de perfil de alunos de Design
}

The usage of user research techniques to define design student profile

\author{
BENJAMIN, Tainá; Graduanda; Faculdade Fucapi \\ tainabenjamin@gmail.com \\ PESSOA, Luna; Graduanda; Faculdade Fucapi \\ lunavicc@gmail.com \\ TEIXEIRA, Narle Silva; Doutora; Faculdade Fucapi \\ narle163@gmail.com
}

\section{Resumo}

Este artigo apresenta o processo e resultado de uma pesquisa acadêmica realizada na disciplina Métodos e Técnicas em Design do curso de Design de uma instituição de ensino superior na cidade de Manaus/AM. O objetivo da pesquisa foi identificar o perfil dos estudantes do curso em questão, compreender seus comportamentos e preferências, gerando personas que serviriam como informação basilar para o projeto de um "Kit Acadêmico de Boas-vindas" para os ingressantes no curso. Para tal, o trabalho teve como principal referência a metodologia de Design Thinking e suas técnicas de pesquisa e compreensão do problema, bem como algumas definições sobre design e a identidade do curso pesquisado. Após a pesquisa, foram criados 2 kits, um atendendo ao estudante com preferência pelo conceito gráfico impresso, e outro para o estudante mais interessado nos temas digitais, ambos ilustrados pela mascote criada para o perfil de estudante identificado na pesquisa.

Palavras-chave: design; metodologia; perfil e alunos.

\begin{abstract}
This paper presents the process and result of an academic research carried out in the discipline Methods and Techniques in Design of the Design course in a higher education institution located in Manaus/AM. The focus of the research was to identify the student profile of the course, to understand their behaviors and preferences, creating personas that would serve as basilar information for the project of a "Welcome Academic Kit" for students. For this, the work had as main reference the Design Thinking methodology, its research techniques and understanding of the problem, as well as some definitions about design and the identity of the researched course. After the research, two kits were created, one serving the student with preference for the printed graphic concept, and another for the student more interested in the digital themes, both illustrated by the mascot created for the student profile identified in the research.
\end{abstract}

Keywords: design; methodology; profile and students. 


\section{Introdução}

A presente pesquisa foi motivada por uma percepção inicial de que os estudantes do curso de Design de uma instituição de ensino superior da cidade de Manaus/AM pareciam apresentar algum padrão de comportamento, de preferências de consumo, e que, por este motivo, seria possível apresentar por meio de um trabalho acadêmico, o perfil do aluno do curso.

Diante de tal inquietação, foi elaborado na disciplina Métodos e Técnicas em Design, um trabalho de pesquisa tendo o seguinte desafio: mapear o perfil dos estudantes do curso para subsidiar a criação de um "Kit Acadêmico de Boas-vindas" para os calouros. Tal problema se justifica pelo fato de que, nos últimos 3 anos a instituição tem recebido um alunado que, aparentemente, são simpáticos aos mesmos ambientes culturais, de conhecimento, e de consumo em geral.

Para tal, os alunos da turma foram divididos em 3 grupos de trabalho, tendo cada grupo realizado um trabalho de observação e pesquisa com o estudante durante o período de permanência no âmbito educacional, com destaque para a compreensão e uso das técnicas de coleta e análise de dados apresentados pelo design thinking. Ao fim do trabalho, cada grupo deveria apresentar um protótipo de média fidelidade do kit criado, com suas devidas justificativas relacionadas ao processo de pesquisa, sendo este artigo o resultado do trabalho de um dos grupos ${ }^{1}$.

A apresentação deste trabalho serve à meta compreensão do processo, quando escrito pelos alunos integrantes da pesquisa, buscando ainda contribuir com a sociedade acadêmica em design pelo estímulo à pesquisas e experiências acadêmicas em campo similar. Além disso, justifica-se sua relevância científica por ter possibilitado conhecer, por meio de procedimentos científicos, o perfil de aluno que o curso em questão possui, informação que antes se apontava de forma subjetiva.

\section{Referencial Teórico}

\subsection{Design e suas competências}

As definições para o design são aplicadas de diversas formas em função dos diferentes contextos em que a área se encontra. Um dos principais fatores que contribuem para que o design não tenha uma única definição é a sua multidisciplinaridade, que favorece o surgimento de diversos pontos de vista.

De acordo com Miller (2004), a palavra design em inglês pode ser usada de duas maneiras, como substantivo e como verbo. Ao exercer sua função de substantivo, geralmente estará se referindo a algum objeto. Já como verbo, normalmente irá se referir a um processo, que é o desenvolvimento do projeto do "produto" que soluciona o problema.

O designer, profissional habilitado para o desenvolvimento de projetos de design, tem seu perfil profissional indicado no artigo $3^{\circ}$ das Diretrizes Curriculares Nacionais do Curso de Graduação em Design no Brasil.

\footnotetext{
${ }^{1} \mathrm{O}$ trabalho acadêmico foi elaborado na disciplina de Métodos e Técnicas aplicados ao Design pelas alunas Andrezza Cavalcante, Luna Pessoa, Mariana Lopes, Nicole Guedes e Tainá Benjamin, no semestre letivo de 2017/2.
} 
O curso de graduação em Design deve ensejar, como perfil desejado do formando, capacitação para a apropriação do pensamento reflexivo e da sensibilidade artística, para que o designer seja apto a produzir projetos que envolvam sistemas de informações visuais, artísticas, estéticas culturais e tecnológicas, observados o ajustamento histórico, os traços culturais e de desenvolvimento das comunidades bem como as características dos usuários e de seu contexto socioeconômico e cultural. (CNE/CES, 2004)

Tal definição de competências profissionais, são detalhadas no artigo $4^{\circ}$ das Diretrizes, apontando ainda, habilidades que coloca o designer como conhecedor do campo produtivo, gerencial e histórico, mas com domínio da criatividade, da estética e da apropriada comunicação dos resultados de seu trabalho.

Para Brown (2010), a função do design é dar realidade a uma prestação conceitual. O fato de ele não ser contínuo e limitado, pois tem restrições, faz com que o design discorde de outras atividades do cotidiano, fazendo com que ele mantenha solidez em sua atuação, possuindo começo, meio e fim. Tal aspecto destacado pelo autor, aponta para a importância do processo de resolução de problemas utilizados pelo designer, onde ao tempo que observa a realidade de forma objetiva, também a interpreta aplicando aos dados toda sua percepção sensível e estética.

Schneider (2010) afirma que atualmente, em função dos diversos fatores como historicidade, aplicação e abrangência da área, é impossível definir com precisão o conceito de design. Todavia, como apontado na Introdução deste trabalho, percebe-se que os jovens ingressantes nos cursos de design, já não tem tanta dificuldade em saber qual será a sua atuação profissional, e quais as técnicas e tecnologias com as quais terá que trabalhar no ambiente acadêmico.

\subsection{0 curso de Design em estudo}

O curso de Bacharelado em Design, onde as pesquisas foram realizadas, tem como ênfase o campo da Interface Digital. O curso foi criado no ano de 2001, com atividades iniciadas em 2002, visando justamente o crescimento do mercado de informática e a importância da interação entre os usuários com os dispositivos eletrônicos.

De acordo com o Projeto Político Pedagógico do Curso (FUCAPI, 2013), uma vez matriculado, o discente irá adquirir capacidade para desenvolvimento de projetos que englobam: interface web, experiência do usuário, multimídias, desenvolvimento de jogos e outros formatos que possuam necessidade de interfaces atrativas e tangíveis. Entretanto, o curso também oferece a formação básica e essencial ao designer, e por este motivo, considera que o seu egresso está também preparado para atuar em projetos de comunicação visual gráfica, não relacionados aos suportes digitais. O curso tem duração de 3 anos e é ofertado anualmente, de modo que, no período da realização da pesquisa, contava com turmas de $2^{\circ}, 4^{\circ}$ e $6^{\circ}$ períodos, cada uma com média de 30 alunos.

Assim, o egresso do curso de Design no qual se desenvolveu o estudo, se torna profissional apto a atuar em diferentes campos, como a indústria, órgãos governamentais, institutos de pesquisa e desenvolvimento, indústria da comunicação e outros, quer seja na iniciativa privada ou pública. Não obstante, dada a expansão da oferta de serviços que envolvem as mais diversas tecnologias digitais, não tem sido raro que alunos e egressos do curso tenham enveredado pelo empreendedorismo, mediante a criação de startups de base tecnológica. 
Dado o perfil e contexto em que o curso se insere, logo percebe-se que ao recrutar seus alunos, torna-se comum receber alunos com interesse em uma cultura digital, como jogos, desenhos, filmes, séries, aplicativos e outras tecnologias de consumo, uma vez que eles possuem os mesmos objetivos profissionais no tocante à área de atuação.

\subsection{Fundamentos do Design Thinking}

Como atividade de conteúdo da disciplina letiva, os alunos deveriam compreender diferentes formas de coletar e analisar o problema por meio da realização do maior número possível de técnicas, sendo priorizada aquelas relacionadas ao Design Thinking.

No Design Thinking se presume na sondagem de informações sobre problemas reais do usuário final, o entendimento da sua jornada e a proposta de soluções compreensíveis que tomam como base o foco no usuário. De acordo com Vianna, et.al (2012) o Design Thinking é composto por três fases principais, sendo elas Imersão, Ideação e Prototipação. Por ser um processo versátil e não-linear, as fases podem ser configuradas de forma que se adequem ao problema.

Conforme os autores, a fase de Imersão pode ser dividida em duas etapas: Preliminar e em Profundidade. A primeira tem como função a compreensão inicial do problema, fazendo parte da mesma o Reenquadramento, a Pesquisa Exploratória e a Pesquisa Desk. A finalidade da Imersão Preliminar é definir o escopo do projeto e suas fronteiras, identificando as informações básicas sobre os usuários. Já na etapa de Imersão em Profundidade, é elaborado um Plano de Pesquisa, utilizando técnicas como: entrevista, observação participante ou indireta, registros fotográficos, entre outras. Neste artigo constam as técnicas de coleta de dados que seriam utilizadas em uma etapa de Imersão em Profundidade, tendo sido a Imersão Preliminar apresentada pela professora orientadora da disciplina.

Após o levantamento de dados na Imersão, o próximo passo é analisar e sintetizar as informações coletadas. Sendo assim, torna-se possível obter padrões e criar desafios que auxiliem no entendimento do problema (VIANNA et al., 2012). Essa etapa de análise conclui as atividades da fase de imersão, e foi realizada pelos alunos com o objetivo de exercitar as diferentes técnicas de síntese.

Seguida da síntese dos dados, é realizada a fase de Ideação, quando as ideias são geradas e apresentadas sem nenhum julgamento, nela ocorre o brainstorming ou outras técnicas que estimulam o pensamento criativo para propor soluções para o problema.

A última fase é a de Prototipação. Em resumo, é a fase de validação das ideias geradas anteriormente, é o momento de tirar as ideias do papel. Deve-se filtrar e ver o que se encaixa no projeto, juntando propostas e colocando a mão na massa. Apesar de ser apresentada como fase final, essa fase também pode ser realizada em paralelo com as outras fases, pois conforme ocorre o surgimento de ideias, elas podem ser testadas e prototipadas. Neste artigo será apresentado somente o protótipo final em rendering digital, embora outros protótipos tenham sido feitos na etapa de ideação.

\section{Metodologia do Trabalho}

A pesquisa teve cenário em uma Instituição de Ensino Superior localizada na cidade de Manaus, Amazonas, Brasil. O estudo foi realizado com 40 alunos do curso de Design da instituição, dentro do período dos meses de outubro e novembro do ano de 2017. 
A investigação se caracteriza como aplicada, pois, tem como objetivo resolver problemas concretos, gerando aplicações práticas e novos conhecimentos resultantes do processo de pesquisa. De acordo com Gil (1999, p. 43) "a pesquisa aplicada possui muitos pontos de contato com a pesquisa pura, pois depende de suas descobertas e se enriquece com o seu desenvolvimento." Assim, pode-se justificar como aplicada, pois o objetivo foi a criação do kit para os alunos ingressantes.

De cunho descritivo, consiste num levantamento de dados e informações caracterizados pela interrogação direta das pessoas cujo comportamento deseja conhecer. Para Trivinos (1987, p.110), "o estudo descritivo pretende descrever "com exatidão" os fatos e fenômenos de determinada realidade", sendo utilizado quando a intenção do pesquisador é conhecer uma determinada característica.

A pesquisa caracteriza-se ainda por uma abordagem qualitativa, que segundo Trivinos (1987), trabalha os dados buscando seu significado, tendo como base a percepção do fenômeno dentro do seu contexto. A pesquisa qualitativa segundo Bogdan \& Biklen (2003), envolve a aquisição de dados descritivos, adquiridos no contato direto do pesquisador com a situação estudada.

O método de design utilizado no projeto teve fortes características do Design Thinking, que é um conjunto de processos para abordar problemas, analisá-los e propor soluções com foco no processo empático do pesquisador, do pensamento visual e na prototipação durante a projetação.

\subsection{Coleta de Dados}

O trabalho de pesquisa em campo foi organizado em duas etapas, em um primeiro momento foi feita a coleta de dados e no segundo momento a análise e síntese do que foi coletado em campo.

$\mathrm{Na}$ etapa de coleta de dados foram utilizadas como forma de exercício e compreensão acadêmica 4 (quatro) técnicas: 1. Observação; 2. Entrevista; 3. Grupo Focal; 4. Questionário.

A primeira técnica utilizada foi a de observação, que consiste em registrar um fato, comportamento ou ação utilizando-se para tal dos sentidos e sensibilidade do pesquisador. $O$ tipo de observação utilizada foi a não-participante, onde o pesquisador se coloca fora do fenômeno observado e não faz nenhuma interferência. A observação foi realizada em grupo (integrantes da equipe em diferentes momentos do ambiente acadêmico) e de forma sistemática. Dessa forma, a equipe elaborou um roteiro de observação, incluindo quais os aspectos a serem observados (forma de se vestir), quando e onde. Após a coleta de dados por todos os integrantes da equipe foi realizada uma reunião para organização e validação dos dados (quadro 01).

Quadro 1: Resultados da técnica de Observação de vestimenta

\begin{tabular}{|c|c|c|}
\hline Vestimenta & Meninos & Meninas \\
\hline Parte de cima & $\begin{array}{c}\text { Camisetas estampadas; camisa de } \\
\text { manga quadriculada; camisetas } \\
\text { monocromáticas; camisetas listradas }\end{array}$ & $\begin{array}{c}\text { Blusas de manga; } \\
\text { regatas quadriculadas; } \\
\text { blusas com listras largas; } \\
\text { blusas com estampas; }\end{array}$ \\
\hline Parte de baixo & $\begin{array}{c}\text { Calças jeans sempre com colorações } \\
\text { escuras: preta e azul escuro }\end{array}$ & $\begin{array}{l}\text { Calças jeans escuras; } \\
\text { saias de tons escuros }\end{array}$ \\
\hline Calçado & $\begin{array}{c}\text { Tênis escuros; coturnos pretos; } \\
\text { chinelos }\end{array}$ & $\begin{array}{c}\text { Sandálias abertas; sapatilhas de cores } \\
\text { diferentes; tênis colorido }\end{array}$ \\
\hline
\end{tabular}

Fonte: Os autores (2017) 
A segunda técnica foi a realização de entrevistas semiestruturadas, onde se obtinha um roteiro de questões como guia, mas que ao mesmo tempo, poderia considerar outros prontos trazidos pelo entrevistado.

Nesta técnica foram entrevistados 5 alunos, sendo 1 aluno do 2 o período, 2 alunos do 4ㅇ período e 2 alunos do 60 período. As entrevistas levaram cerca de 10 minutos e foram realizadas no campus da faculdade.

Nas entrevistas foi possível obter informações sobre as predileções e simpatias dos alunos em relação a entretenimento, vida pessoal e acadêmica. 0 quadro 02 apresenta em palavras isoladas o quê surgiu nas respostas, sendo os itens de título o roteiro da entrevista.

Quadro 2: Resultados da técnica de Entrevista

\begin{tabular}{|c|c|c|c|c|c|c|c|}
\hline $\begin{array}{l}\text { Tempo } \\
\text { Livre }\end{array}$ & $\begin{array}{l}\text { Atividades } \\
\text { relacionadas } \\
\text { a design }\end{array}$ & Séries/Filmes & Livros & Música & Roupas & Despesas & Jogos \\
\hline Comer & $\begin{array}{c}\text { Ilustrações } \\
\text { Manuais }\end{array}$ & $\begin{array}{c}\text { House of } \\
\text { Cards }\end{array}$ & $\begin{array}{l}\text { Torre } \\
\text { Negra }\end{array}$ & Rock antigo & $\begin{array}{l}\text { Camisas } \\
\text { coloridas }\end{array}$ & $\begin{array}{c}\text { Filmes/Livr } \\
\text { os }\end{array}$ & $\begin{array}{c}\text { Don't } \\
\text { Starve } \\
\text { Together }\end{array}$ \\
\hline Jogos & $\begin{array}{c}\text { llustrações } \\
\text { Digitais (mesa } \\
\text { digitalizadora) }\end{array}$ & Vikings & $\begin{array}{c}\text { Saga } \\
\text { Millenium }\end{array}$ & $\begin{array}{c}\text { Música } \\
\text { instrumental }\end{array}$ & $\begin{array}{c}\text { Roupas } \\
\text { pretas e } \\
\text { cinzas }\end{array}$ & $\begin{array}{c}\text { Materiais } \\
\text { para } \\
\text { desenho }\end{array}$ & $\begin{array}{l}\text { PES/ } \\
\text { FIFA }\end{array}$ \\
\hline Séries & $\begin{array}{c}\text { Criação de } \\
\text { projetos para } \\
\text { plataformas } \\
\text { digitais }\end{array}$ & Supernatural & Design & $\begin{array}{l}\text { Trilhas } \\
\text { sonoras }\end{array}$ & $\begin{array}{c}\text { Roupas } \\
\text { confortáveis }\end{array}$ & $\begin{array}{l}\text { Cursos } \\
\text { online }\end{array}$ & $\begin{array}{c}\text { League of } \\
\text { Legends }\end{array}$ \\
\hline Cinema & $\begin{array}{l}\text { Criação de } \\
\text { projetos } \\
\text { físicos }\end{array}$ & Breaking Bad & História & Reggae & Bermuda & Comida & Siege \\
\hline
\end{tabular}

Fonte: Os autores (2017)

A terceira técnica foi a de grupo focal, que para Kitzigner (2000) consiste em uma forma de entrevistas realizada com grupos, baseada na comunicação e na interação, tendo como objetivo principal reunir informações detalhadas sobre um tópico essencial (sugerido por um pesquisador ou moderador do grupo) a partir de um grupo de participantes selecionados.

Na presente pesquisa foram realizados dois grupos de foco. O primeiro ocorreu no período de 1 hora, com 2 alunos do 4 período, 1 aluno do 2ㅇ período e 1 aluno do 6ㅇ período. Neste grupo os participantes foram orientados a escolher imagens que os representassem quanto aos seus gostos e preferências, tendo como fonte de pesquisa uma rede social de compartilhamento de fotos, onde os usuários podem compartilhar e gerenciar imagens temáticas. Após a escolha individual, foi montado um único painel que contém todas as imagens selecionadas, sendo visível que a maioria se repetia. A figura 01 ilustra as categorias de imagens selecionadas pelos participantes da técnica. 
Figura 01: Painel visual pelo Grupo Focal

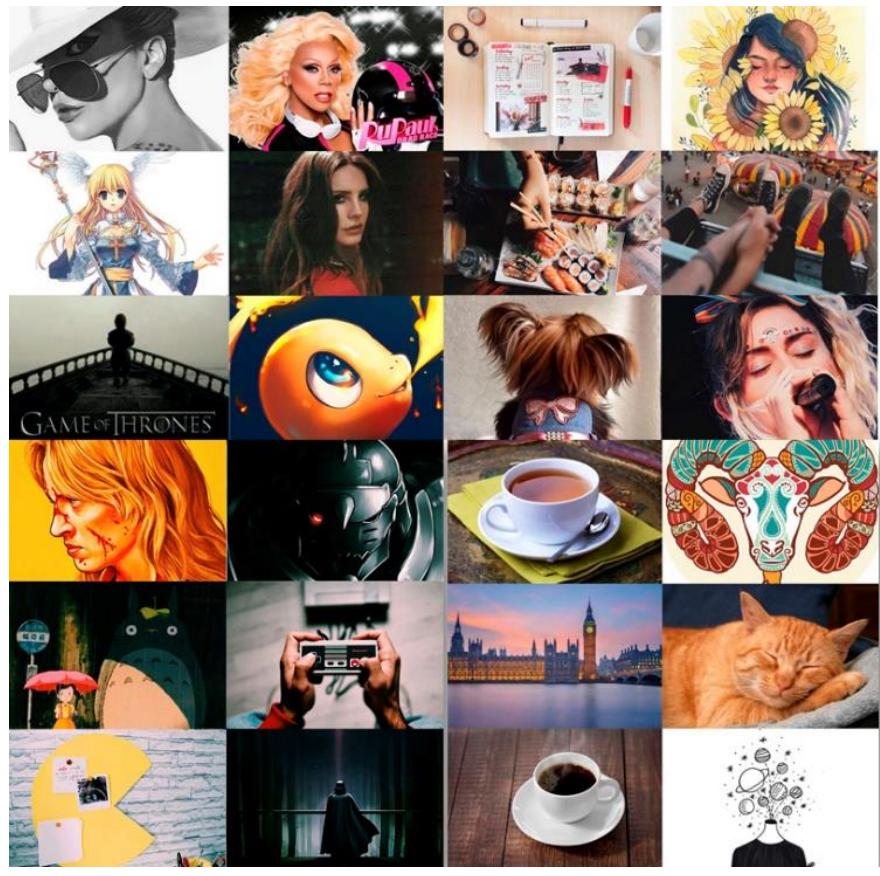

Fonte: Os autores, com Imagens coletadas do site https://br.pinterest.com/. (2017)

No segundo grupo focal, foram pré-definidos temas de interesse e solicitado para que discutissem de forma coletiva sobre o assunto, explanando suas opiniões e apontando os seus favoritos. Nesse momento, participaram da experiência (que teve duração de 30 minutos), 6 alunos do 4 ㅇ período, 2 alunos do $2 \circ$ período e 1 aluno do 60 período. 0 quadro 3 apresenta as respostas apontadas pelos alunos.

Quadro 3: Favoritos pelo Grupo Focal

\begin{tabular}{|c|c|c|c|c|c|c|}
\hline Comida & Design & Séries & Youtube & Jogos & Roupas & Desenhos \\
\hline Sushi & Ilustrações & Vikings & Nerdologia & MOBA & Calça Jeans & Gravity Falls \\
\hline Café & $\begin{array}{l}\text { Projetos } \\
\text { Digitais }\end{array}$ & Narcos & Jovem Nerd & Smite & Camiseta & Scooby Doo \\
\hline $\begin{array}{l}\text { Comida } \\
\text { Regional }\end{array}$ & $\begin{array}{c}\text { Técnicas de } \\
\text { desenho }\end{array}$ & $\begin{array}{l}\text { Game of } \\
\text { Thrones }\end{array}$ & Entre Planos & $\begin{array}{l}\text { League of } \\
\text { Legends }\end{array}$ & $\begin{array}{c}\text { Roupas } \\
\text { Confortáveis }\end{array}$ & $\begin{array}{c}\text { Rick and } \\
\text { Morty }\end{array}$ \\
\hline Lasanha & $\begin{array}{l}\text { Blogs de } \\
\text { Design }\end{array}$ & O Atirador & Cellbit & Warface & Moletom & $\begin{array}{c}\text { Steven } \\
\text { Universe }\end{array}$ \\
\hline
\end{tabular}

Fonte: Os autores (2017)

A última técnica aplicada foi o questionário, que assim como as técnicas anteriores, teve como objetivo conhecer opiniões, sentimentos e interesses dos entrevistados. Optou-se pelo modelo misto, com perguntas abertas e fechadas, sendo as fechadas elaboradas por uma Escala de Diferencial Semântico. 
O questionário foi aplicado a 31 alunos, sendo 11 alunos do 20 período, 9 alunos do 4 ㅇ período e 11 alunos do 6으odo. A figura 2 apresenta uma imagem do questionário utilizado.

Figura 2: Modelo de questionário aplicado

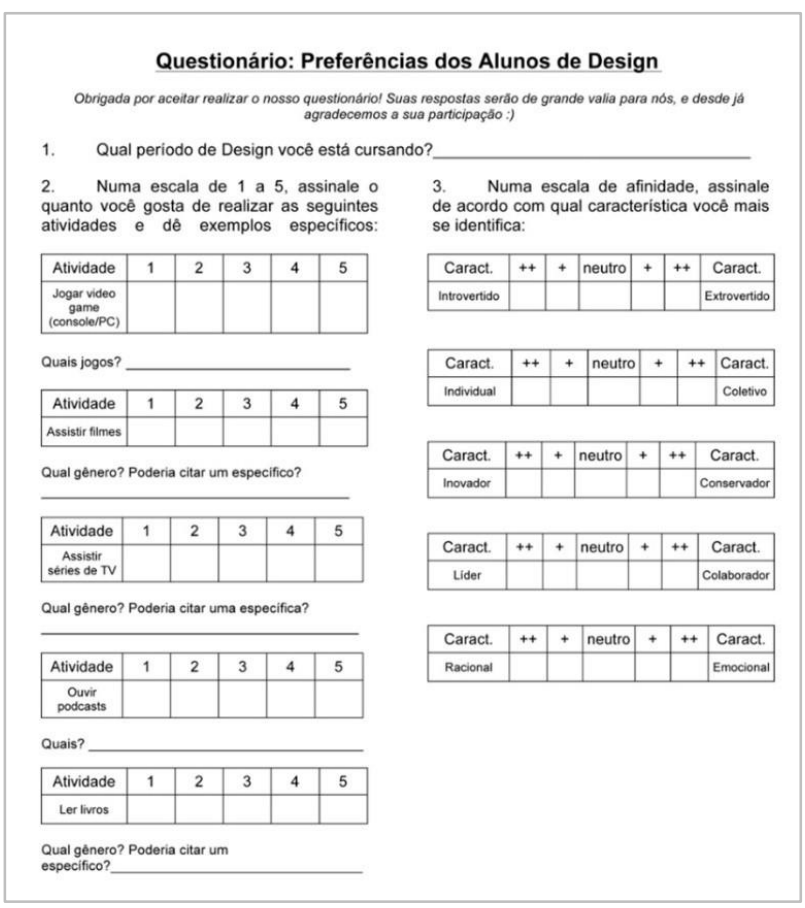

Fonte: Os autores (2017)

Após aplicado, os dados dos questionários foram tratados e organizados na tabela 1 , sendo possível perceber com mais clareza os indicadores quantitativos gerados pela escala de diferencial semântico. Os dados qualitativos foram separados para integrar a análise e síntese a ser realizada posteriormente.

Tabela 1: Resultados dos dados coletados no Questionário

\begin{tabular}{|cccccc|c|}
\hline ATIVIDADE & $\mathbf{0}$ & $\mathbf{1}$ & $\mathbf{2}$ & $\mathbf{3}$ & $\mathbf{4}$ & $\mathbf{5}$ \\
\hline Jogar & - & 2 & 2 & 8 & 4 & 15 \\
Filmes & - & 0 & 0 & 8 & 7 & 16 \\
Séries & 1 & 3 & 0 & 10 & 9 & 8 \\
Podcasts & 18 & 4 & 2 & 2 & 1 & 4 \\
\hline Livros & 1 & 6 & 5 & 10 & 4 & 5 \\
\hline
\end{tabular}

Fonte: Os autores (2017) 
Tabela 2: Resultados dos dados coletados no Questionário

\begin{tabular}{ccccccc|}
\hline CARACT. & ++ & + & $\mathbf{0}$ & + & ++ & CARACT. \\
\hline Introvertido & 4 & 5 & 8 & 8 & 6 & Extrovertido \\
Individual & 3 & 7 & 8 & 8 & 5 & Coletivo \\
Inovador & 7 & 10 & 12 & 1 & 1 & Conservador \\
Líder & 7 & 7 & 7 & 4 & 6 & Colaborador \\
Racional & 4 & 10 & 7 & 7 & 4 & Emocional \\
\hline
\end{tabular}

Fonte: Os autores (2017)

Como dito anteriormente, a diversidade de técnicas aplicadas tinha como objetivo gerar uma compreensão teórico-prática de uma única pergunta-problema. Assim, algumas vezes as questões coletadas se repetiram, e seus resultados serviram para complementar ou validar outros dados já obtidos.

\subsection{Análise e Síntese}

Após a coleta de dados, foi dado início a análise e síntese dos resultados obtidos, visando interpretar e compreender o que foi coletado. Segundo Rampazzo (2005) com a ausência da análise, todo conhecimento se torna confuso e superficial, enquanto sem a síntese, é fatalmente inacabado.

Nesta etapa foram utilizadas 7 técnicas: 1. Cartões de Insight; 2. Diagrama de Afinidades; 3. Painel Semântico; 4. Mapa Conceitual; 5. Personas; 6. Mapa de empatia; 7. Critérios Norteadores.

Os cartões de insight são "reflexões embasadas em dados reais das pesquisas exploratórias[...], transformadas em cartões que facilitam a rápida consulta e manuseio" (VIANNA, et.al, 2012). Todos os dados qualitativos gerados nas diferentes técnicas de coleta de dados foram considerados para a geração dos cartões. Após a criação dos cartões, de forma ordenada foi gerado o Diagrama de Afinidades, que se caracteriza pela "organização e agrupamento dos Cartões de Insights com base em afinidade, similaridade, dependência ou proximidade, gerando um diagrama que contém as macro áreas que delimitam o tema trabalhado, suas subdivisões e interdependências" (VIANNA, et.al, 2012).

Figura 3: Cartões de Insight e Diagrama de Afinidades

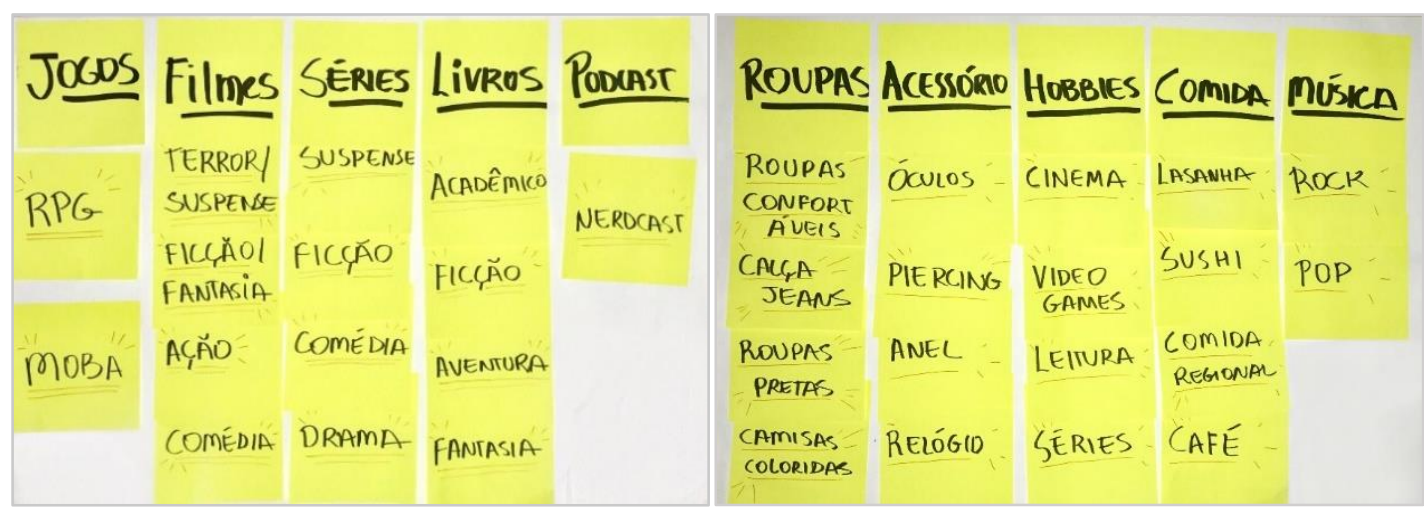

Fonte: Os autores (2017) 
O painel semântico caracteriza-se por ser uma técnica de representação qualitativa dos dados analisados. Para sua construção foram elaboradas ilustrações que representam o públicoalvo quanto as preferências relacionadas ao entretenimento, formando uma composição de imagens interdependentes.

Figura 4 - Painel Semântico

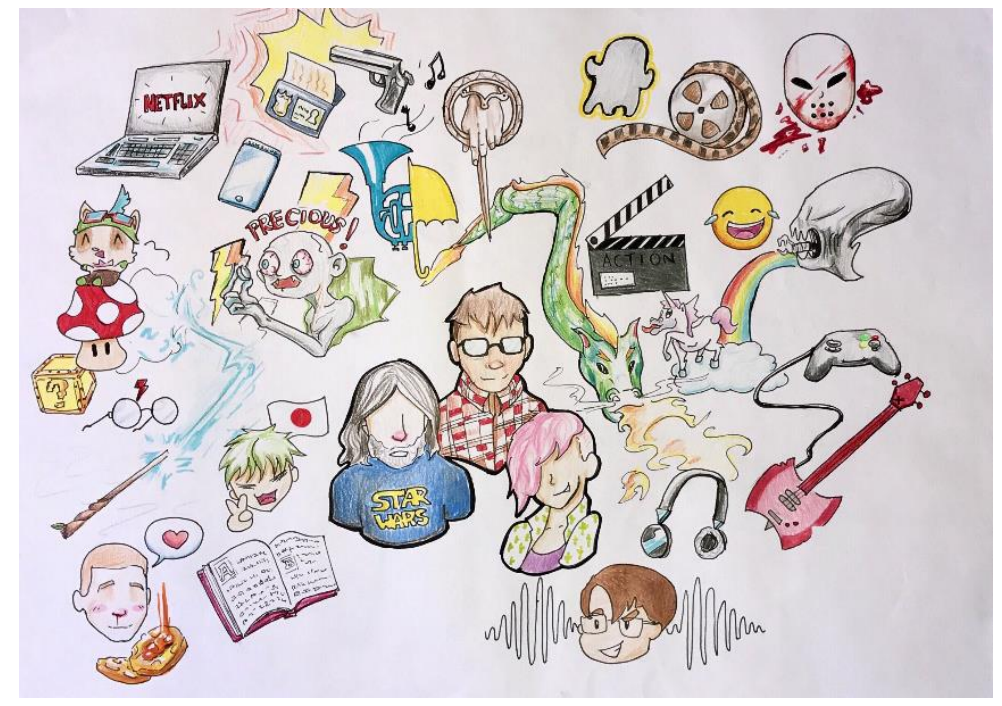

Fonte: Os autores (2017)

A quarta técnica foi o Mapa Conceitual, que consiste em um diagrama de palavras e desenho de conexões com o objetivo de organizar ideias, conceitos e informações abstratas de forma visual e de modo esquematizado. Nele reuniu-se o conteúdo em forma de teia de aranha, sendo possível identificar os subtemas presentes em cada tópico e analisá-los (vide figura 5).

Figura 5: Mapa Conceitual

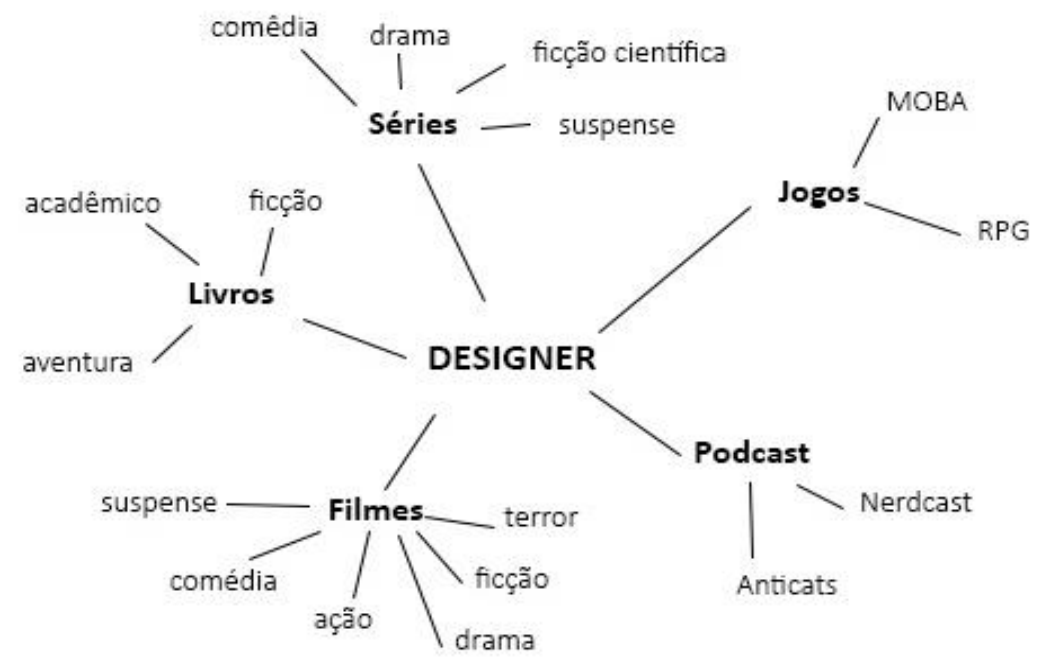

Fonte: Os autores (2017) 
A partir da análise e síntese destas técnicas sobre os comportamentos observados pelo público-alvo em estudo, foram criados personagens fictícios, apresentando características e estereótipos surgidos da pesquisa. Esses estereótipos são chamados de "Personas", conforme o quadro 4.

Quadro 4: Criação de Personas

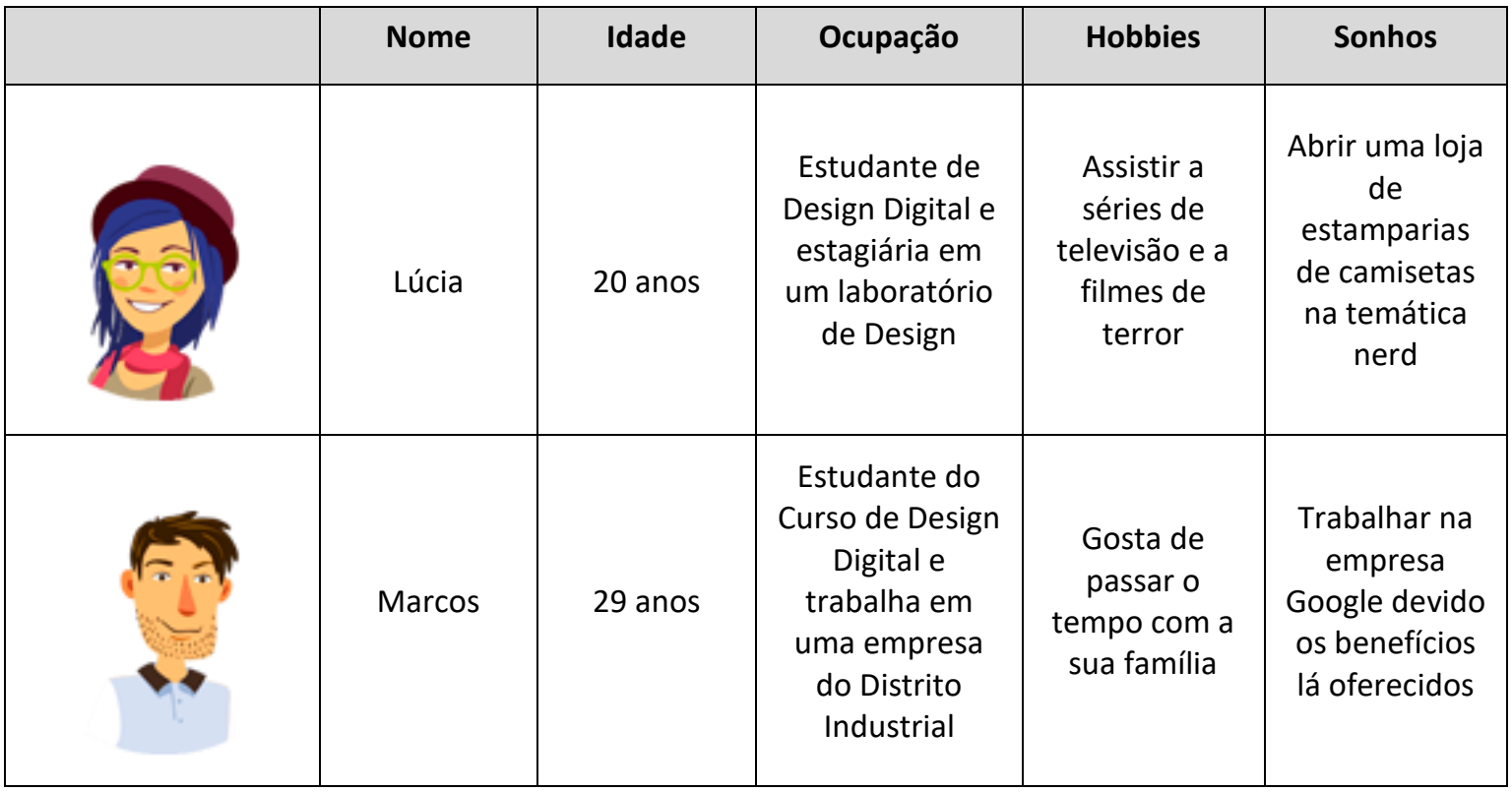

Fonte: Os autores (2017)

Após a criação das personas, foi elaborado o Mapa de Empatia, que consiste em organizar visualmente quatro informações estratégicas sobre o público em estudo, são elas: o que faz e fala, o que vê, o que pensa e sente e o que escuta. Mais uma vez, com base nos resultados anteriores de todas as etapas de análise do público-alvo, foi possível analisar e conectar as informações como um esquema mental, de forma que representasse a maneira como um estudante de Design da faculdade se sente e se comporta (vide figura 6).

Figura 6: Resultado Mapa de Empatia

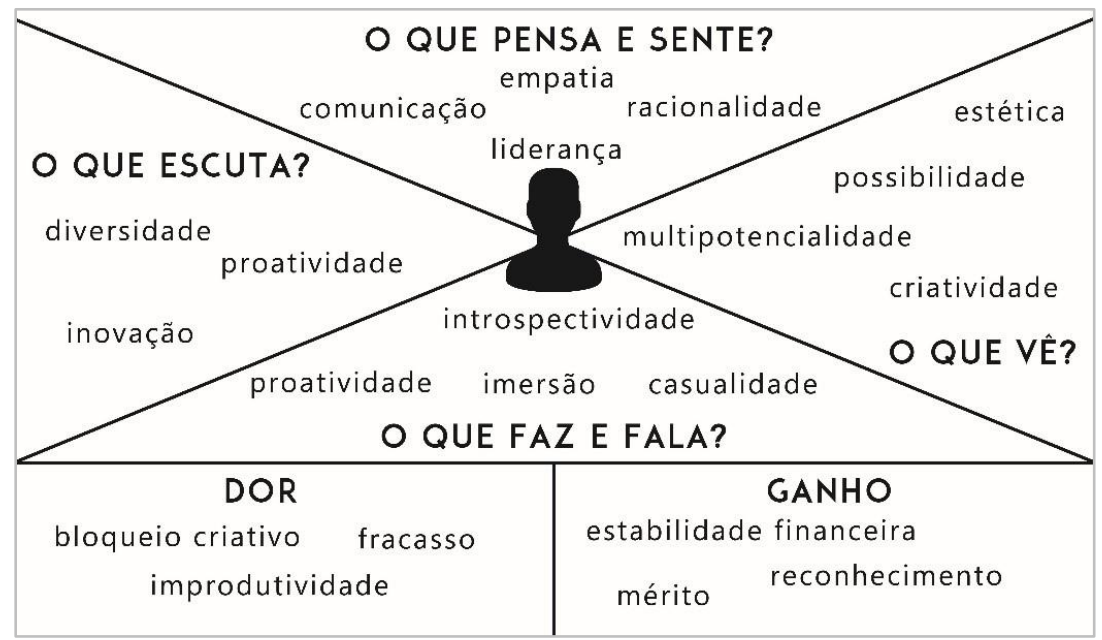

Fonte: Os autores (2017) 
Por fim, foram definidos os Critérios Norteadores, que servem como base final para a determinação dos limites do projeto e do seu verdadeiro propósito, dando um direcionamento mais adequado e exato ao objetivo do trabalho. Nesse caso, os critérios norteadores descritos para a fase de Ideação foram 4: ser duradouro, memorável, unissex e portátil.

\subsection{Ideação}

Uma vez definidos os critérios norteadores, partiu-se para a fase de Ideação. Inicialmente fora utilizada a técnica do brainstorming, que consiste em utilizar uma base quantitativa, analisando as informações previamente coletadas, listando a maior quantidade possível de ideias para solucionar o problema - "brainstorming baseia-se no princípio: 'quanto mais ideias, melhor "” (BAXTER, 2008, p. 68).

Como exercício foi realizado também o Método 635, que é uma técnica criativa que de acordo com ORTIZ (2014), estimula o pensamento divergente, utilizando a livre associação como base de raciocínio, aumentando a produção de ideias criativas, característica valiosa em diferentes contextos.

O refinamento das ideias do brainstorming e do Método 635 foi feito através da técnica de MESCRAI, que para Baxter (2008, p. 80), “[...] uma sigla de 'Modifique (aumente, diminua.), Elimine, Substitua, Combine, Rearranje, Adapte, Inverta'. Esses termos funcionam como uma lista de verificação para estimular possíveis modificações no produto".

Por último, foram selecionadas 3 ideias de todas as geradas para análise mediante uma Matriz de Posicionamento, que é uma técnica em que cada ideia é avaliada levando em consideração os critérios norteadores e as necessidades das personas, completando assim o processo de decisão.

\section{Resultados}

Após todas as etapas finalizadas e cuidadosamente analisadas, constatou-se que os alunos da instituição poderiam ser divididos em dois grupos amplos: os que gostavam de fazer seus projetos voltados à parte gráfica de forma manual e outro grupo que tinha preferência a executar seus trabalhos digitalmente e que fossem expostos em plataformas digitais. Essas diferenças foram interpretadas através dos resultados coletados principalmente nas técnicas de Grupo Focal e Entrevista, onde é possível observar a presença dessas preferências dentro do tópico referente a atividades relacionadas a design.

A criação dos critérios norteadores adicionou características aos kits de forma perspicaz. A característica de unissex, por exemplo, foi um aspecto surgido no Mapa de Empatia, estimulando assim o respeito à diversidade. Outro critério levado em consideração foi o preço de produção, pois o foco seria atender a todos os calouros sem que fosse necessário um custo alto.

$\mathrm{Na}$ fase de ideação, foi apontado como parte da solução uma materialização dessa personalidade do aluno de design por meio da criação de uma mascote para o curso. A escolha de uma mascote para essa representação se encaixou de forma perspicaz.

Nomeado de "Dedê", a mascote se materializa em formato de um personagem divertido, curioso e criativo, que sintetiza o espírito dos estudantes ávidos por conhecimento e oportunidades. Para isso, sua roupa verde-água incorpora a essência jovem (verde para esperança e liberdade) com o elemento da ponderação (proporcionada pelo azul). A combinação cromática como um todo - 
amarelo, coral e rosa claro - remete à uma linguagem visual "cartunesca", e a escolha de tons leves reforça a ideia de energia e jovialidade. A cabeça em formato de telinha e uma silhueta arredondada busca caracterizar uma personalidade amigável.

Aos alunos que se identificavam com trabalhos mais manuais, fora criado o Kit CMYK, pois esta sigla se refere a trabalhos impressos, e aos alunos que se identificam com os trabalhos digitais, surgiu a necessidade da criação do Kit RGB, sigla que representa a reprodução de cores em dispositivos eletrônicos (vide figura 7).

Figura 7: Kit CMYK e RGB

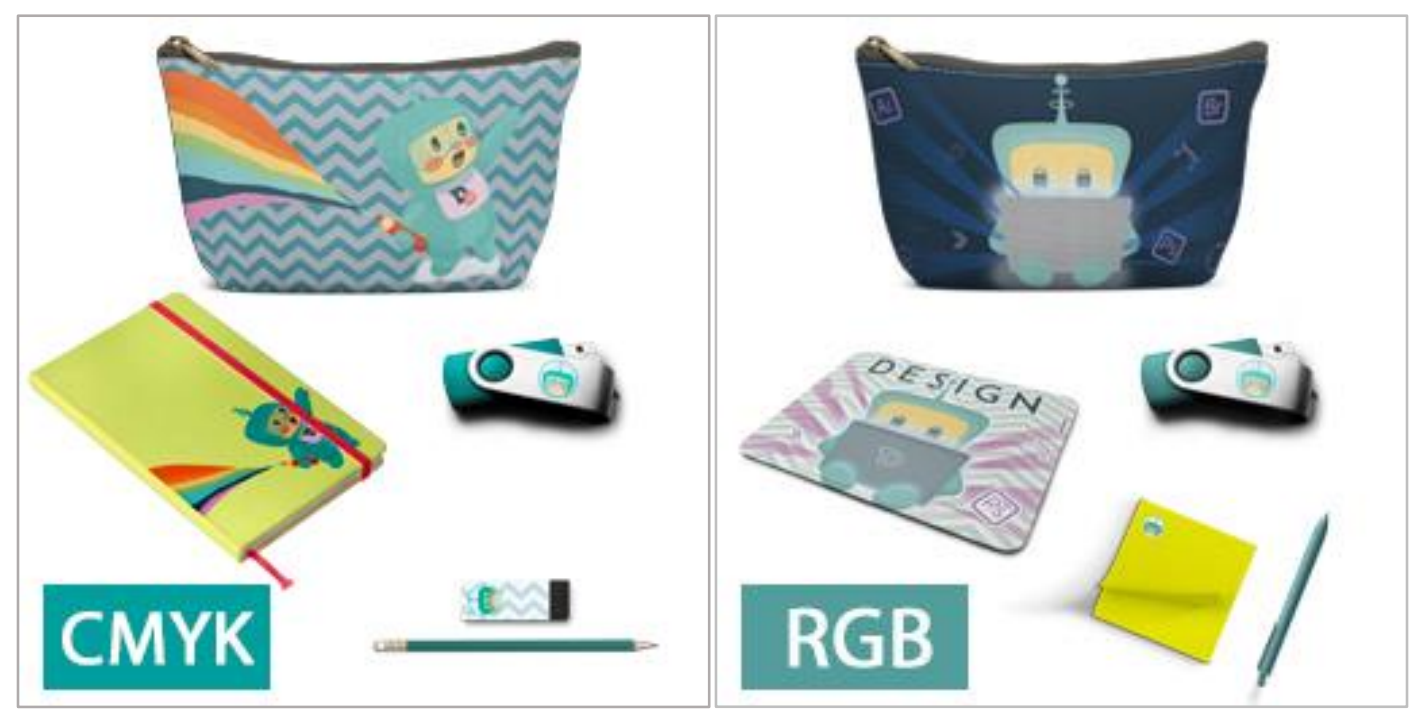

Fonte: Os autores (2017)

A disposição dos dois modelos de kits para os ingressantes possui a seguinte organização: Kit CMYK consiste em uma bolsa/estojo estilizada com a mascote do curso, contendo em seu interior um mini sketchbook, um pendrive, um lápis e uma borracha, objetos que visam trazer maior agilidade ao processo criativo gráfico - o pendrive, embora de uso plenamente digital, foi mantido no kit CMYK pelo valor comercial, o que deveria despertar grande interesse do estudante.

O Kit RGB consiste em uma bolsa/estojo também estilizada com a mascote do curso, e como componentes internos um mousepad, um pendrive, um bloco de notas adesivas e uma caneta tipo pincel. O mousepad com intuito de facilitar o uso da ferramenta mouse que é bastante utilizado em projetos digitais, o pendrive tem como função o transporte de dados - já o bloco de notas adesivas juntamente a caneta visa a criação de notas rápidas, elementos que embora de uso gráfico, são muito utilizados para o desenho de projetos digitais.

O objetivo da distribuição dos kits aos alunos ingressantes do curso é compreendido como uma maneira de recebê-los de uma forma acolhedora e inspiradora, dando-lhes a sensação de hospitalidade e identificação com o curso de Design.

\section{Conclusão}

O trabalho apresentado neste artigo teve como objetivo mapear o perfil dos estudantes de um curso de Design em Manaus/AM, a fim de subsidiar a criação de um "Kit Acadêmico de Boasvindas" para os seus calouros. 
Para tal, fez uso de diversas técnicas de levantamento de dados, análise e síntese, sendo possível identificar que os estudantes do curso, embora pudessem ser identificados em faixa etária distintas, apresentam clara conexão entre seus gostos e preferências de consumo.

Por se tratar de um projeto acadêmico, o estudo se limitou a uma instituição de ensino, porém, considera-se que poderia ser realizado um estudo mais amplo, expandindo para análises de outras instituições ou até mesmo da região, sendo possível identificar similaridades ou diferenças entre os alunos em sua relação com o perfil da matriz curricular de seu curso, de sua localidade ou outras variáveis identificáveis.

Espera-se que a apresentação desta pesquisa possa suscitar outras investigações que tenham como sujeito o próprio aluno de design, onde suas preferências possam servir de filtro para a criação de produtos, processos, metodologias, eventos da área e demais atividades acadêmicas. 


\section{Referências}

BAXTER, Mike. Projeto de produto: Guia prático para o design de novos produtos. São Paulo: Edgard Blucher, 2008.

BOGDAN, R. S.; BIKEN, S. Investigação qualitativa em educação: uma introdução à teoria e aos métodos. 12.ed. Porto: Porto, 2003.

BROWN, Tim. Design Thinking: Uma Metodologia Poderosa para Decretar o Fim das Velhas Ideias. Tradução Cristina Yamagami. Rio de Janeiro: Elsevier, 2010.

CNE/CES. Diretrizes Curriculares Nacionais do Curso de Graduação em Design. In: Portal MEC, 2004. (http://portal.mec.gov.br/cne/arquivos/pdf/rces05_04.pdf..)

FUCAPI. Projeto Político Pedagógico do Curso de Design. FUCAPI, 2013.

GIL, Antonio C.; Métodos e Técnicas de Pesquisa Social. 5. ed. São Paulo: Atlas, 1999.

KITZINGER, J. Focus groups with users and providers of health care. In: POPE, C.; MAYS, N. (Org.). Qualitative research in health care. 2. ed. London: BMJ Books, 2000.

ORTIZ, Felipe. Métodos de criatividade para a gestão de projeto inovadores. Revista Inovação Tecnológica, São Paulo, 2014.

SCHNEIDER, Beat. Design - Uma Introdução: O Design no Contexto Social, Cultural e Econômico. São Paulo: Blücher, 2010.

TRIVIÑOS, A. N. S. Introdução à pesquisa em ciências sociais: a pesquisa qualitativa em educação. São Paulo: Atlas, 1987.

VIANNA, M.; VIANNA, Y.; ADLER, I.; LUCENA, B.; RUSSO, B. Design Thinking: Inovações nos Negócios. Rio de Janeiro: MJV Press, 2012. 